\title{
Ser mulher e cineasta no Brasil: percursos invisíveis
}

\author{
Carla Conceição da Silva Paiva*
}

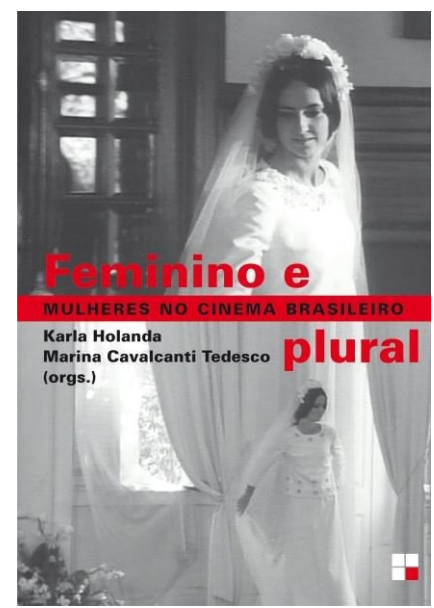

Karla Holanda \& Marina Cavalcanti Tedesco (Org.). (2017). Feminino e plural: mulheres no cinema brasileiro. Campinas, SP: Papirus. ISBN 978-85-449-02653.

As mulheres sempre estiveram presentes no cinema brasileiro, atuando como atrizes, mas também trabalhando na indústria cinematográfica, ocupando as mais diversas funções, como já delinearam Elice Munerato e Maria Helena Darcy (1982), no livro "As musas da matinê", e Heloísa Buarque de Hollanda (1989), em "Quase catálogo 1: realizadoras de cinema no Brasil (1930-1988)". Essa incorporação atrás das câmeras contribuiu para a construção de uma multiplicidade de outras imagens das mulheres, principalmente, a partir da década de setenta, auge do movimento feminista no solo brasileiro. Contudo, salientamos que, ainda hoje, a história e os estudos cinematográficos nacionais tratam timidamente a participação feminina no audiovisual, corroborando para as enormes desigualdades de gênero presentes nas relações sociais, fato facilmente comprovado pela tímida publicação destinada a análise e exposição dessas temáticas. Ser mulher e cineasta no Brasil, infelizmente, ainda significa ser invisível.

* Universidade do Estado da Bahia - UNEB, Campus III, Juazeiro, Departamento de Ciências Humanas, Programa de Pós-Graduação em Educação, Cultura e Territórios Semiáridos - PPGESA. 41.150-000, Salvador, Brasil. E-mail: cpaiva@uneb.br 
Nesse contexto, após um lapso conceitual de quase trinta anos, o livro "Feminino e plural: mulheres no cinema brasileiro", organizado por Karla Holanda e Marina Cavalcanti Tedesco, destaca-se por apresentar um amplo panorama do cinema feito por mulheres no Brasil, para além de seu anonimato e críticas infundadas, abrangendo diversos períodos da história, perspectivas, campos de atuação e tons variados de abordagens que demonstram a pluralidade do feminino no campo audiovisual e a emergência da produção e difusão de informações sobre gênero, cinema e história. Partindo do pressuposto de que, dentro ou fora das telas, o trabalho feminino no cinema ainda é invisibilizado, as duas organizadoras reuniram pesquisas desenvolvidas nos últimos anos sobre realizadoras e obras pouco conhecidas e convocaram outros homens e mulheres para transferir seus repertórios teóricos e metodológicos ao recorte de autoria feminina. Como resultado, oferecem uma coletânea de dezesseis capítulos que destacam as mais diversas formas de participação das mulheres no cinema brasileiro, oferecendo perspectivas para novas investigações, relações e associações pouco exploradas no campo da história de gênero e cinema.

Logo no primeiro texto, intitulado "Cléo de Verberena e o trabalho da mulher no cinema silencioso brasileiro", Luciana Corrêa de Araújo, descreve o trabalho feminino atrás das câmeras no cinema silencioso brasileiro, a partir da atuação de Cléo de Verberena (primeira diretora do cinema brasileiro) e Carmem Santos (atriz e produtora), mapeando também protagonistas dos filmes dessa época, que exerceram uma profissão fora do âmbito doméstico nas telas, concluindo que as hierarquias de gênero e o conservadorismo nacional conduziram a fortes restrições e subordinação nas experiências realizadas por essas duas mulheres, suas conquistas e seus limites frente a ameaça ou a concorrência à autoridade masculina. Em seguida, Sheila Schvarzman, em "Gilda Bojunga: caminhos e percalços de uma afirmação", percorre a trajetória de Gilda Roquette Bojunga, desde sua entrada como assistente educativa no Instituto Nacional do Cinema educativo - INCE, passando por suas atividades como realizadora de filmes - Yes, I love Paris (1967) e Memória de uma época (1979-1980) - até sua atuação como gestora em outros organismos oficiais do cinema brasileiro, onde mediou as relações entre cinema e educação, para analisar brechas pequenas e devidamente ocultadas de atuação feminina no cinema brasileiro.

Na sequência, em "Cinema brasileiro (moderno) de autoria feminina", Karla Holanda, utilizando autoras feministas como Teresa de Lauretis, Joan Scott e Virginia Woolf, analisa o cinema feito por mulheres nas décadas de 1960 e 1970, sinalizando nuances que aproximam e distanciam essas diretoras do cinema novo e do cinema marginal feito por homens, nesse período, por 
apresentar gradações discursivas sobre a condição feminina e elementos do campo audiovisual que insinuam um acostamento com o denominado contracinema. O quarto capítulo - "Cineastas brasileiras (feministas) durante a ditadura civil-militar" - escrito por Alcilene Cavalcante, engendra as ideias feministas sobre a opressão das mulheres, que envolvem a repressão à sexualidade e a invenção de modos de existência distintos, materializados na expressão de personagens que resultam das tendências de três cineastas brasileiras - Maria do Rosário Nascimento e Silva, Vera de Figueiredo e Adélia Sampaio, primeira cineasta negra. Em "Estéticas e políticas de resistência no "cinema de mulheres' brasileiro (anos 1970 e 1980)", a autora Ana Maria Veiga responde a duas questões principais: que novas estéticas foram produzidas pelos filmes Os homens que eu tive (1973), de Tereza Trautman, e Das tripas coração (1982), de Ana Carolina, em diálogo com a ditadura militar e o movimento feminista e se, para além da questão estética, esses filmes recobrem relações políticas e emocionais, concluindo que essas duas diretoras fizeram emergir linhas estético-políticas perturbadoras acerca dos direitos das mulheres ao corpo e à sexualidade, radicalizando em um conjunto denominado "cinema de mulheres". Ato contínuo, ainda sobre a participação das mulheres na direção de filmes brasileiros e sua ligação com a ebulição do movimento feminista, Mariana Ribeiro Tavares evidencia a coragem de Helena Solberg na realização de filmes que promovem a contestação sobre diferentes aspectos da realidade brasileira, sem perder de vista o contexto social, econômico e político das Américas, dialogando com a reportagem televisiva, o documentário participativo, o clássico e o contemporâneo, cobrindo um extenso período de lutas e reinvindicações de mulheres nesse continente, como o sufrágio universal, direito ao divórcio e a exploração do trabalho feminino, em "Helena Solberg: militância feminista e política nas américas".

Ainda focado na década de 1970, no sétimo capítulo, intitulado "O discurso historiográfico em mulheres de cinema", Luís Alberto Rocha Melo reflete sobre o processo de realização cinematográfico de Ana Maria Magalhães, com base em seu trabalho pioneiro - o média metragem Mulheres de cinema (1977) -, que se contrapõe à tradição de uma historiografia masculina, apresentando personagens femininas, como Leila Diniz, para construir uma narrativa panorâmica e cronológica que retrata a participação feminina na história da atividade cinematográfica no Brasil. Na sequencia, Érica Sarmet e Marina Cavalcanti Tedesco, em "Articulações feministas no cinema brasileiro nas décadas de 1970 e 1980", ressaltam as experiências da Associação Brasileira de Mulheres do Cinema e do Coletivo de Mulheres de Cinema e Vídeo do Rio de Janeiro, como uma espécie de re-visão da história das mobilizações políti- 
cas das mulheres no cinema brasileiro, acreditando que faz-se necessária uma transposição acrítica de modelos do passado para pensar o presente. Ambas autoras defendem que essas experiências podem colaborar para a organização das ações pulverizadas e descentralizadas de associações nacionais e regionais que atuam contemporaneamente em nome das mulheres. Depois, Alessandra Soares Brandão e Ramayana Lira de Sousa, no texto "Cassandra Rios e o cinema erótico brasileiro: autoria e perfomatividade", reconhecendo o duplo anonimato das mulheres roteiristas - excluídas por seu gênero e pela função que exercem -, de forma assumidamente panorâmica, discutem a autoria da romancista Cassandra Rios na adaptação de sua obra A paranoica (1976) para as telas, a partir da ampliação das discussões de Judith Mayne sobre a autoria feminista no cinema; e do processo de criação cinematográfica e da singularidade do trabalho dessa roteirista, por sua ambiguidade estética e política, pensadas a partir de Judith Butler. Analisando possíveis marcas de performatividade de autoria dessa escritora lésbica, as duas autoras acastelam que a romancista se distendeu como roteirista para expor diferenças de um universo de perversão e possibilidade feminino no cinema popular erótico.

No capítulo 10, "Protagonismos experimentais femininos no surto superoitista dos 1970", Rubens Machado Júnior e Marina da Costa Campos perfilham a participação feminina nos trabalhos superoitistas desenvolvido no Brasil, a partir da década de 1970, ressaltando o caráter divinatório e o protagonismo de mulheres que atuaram na produção coletiva de filmes como $A$ mulher de todos (1970), assumindo funções técnicas - produção, fotografia, direção, montagem etc. - ou estrelando histórias que subvertiam as relações de produção e circulação cinematográfica. Logo após, Gilberto Alexandre Sobrinho constata a violenta invisibilidade, nas telas brasileiras, das mulheres negras e a força da produção documental como uma estratégia política de representação e empoderamento dos sujeitos, apresentando documentários dos anos 1980 e 1990 que parecem antecipar o denominado "Feminismo Negro", por focalizarem no tom militante e no engajamento político explícito, como Mulheres negras (1986), de Márcia Meireles e Silvana Afram. Sobrinho, ainda no seu texto, intitulado "Identidade, resistência e poder: mulheres negras e a realização de documentários", analisa o longa Ori (1989), de Raquel Gerber, delimitando como a construção da identidade negra e a diáspora são construídos por imagens e sons em um complexo processo de representação, bem como traça um panorama da produção recente de trabalhos de jovens realizadoras negras que articulam identidade, resistência e poder nos seus filmes. Na sequência, dando continuidade a temática "invisibilidade das mulheres negras no cinema brasileiro", Ceiça Ferreira e Edileuza Penha de Souza, no capítulo "Formas de 
visibilidade e (re)existência no cinema de mulheres negras", avaliam $O$ dia de Jerusa (2014), de Viviane Ferreira, e Aquém das nuvens (2010), de Renata Martins, partindo do conceito de "cinema negro feminino", para designar uma concepção de cinema que rompe com a imposição de imagens e lugares sociais de subalternidade e hipersexualização das mulheres negras presentes no cinema e na televisão. Antes disso, essas autoras discutem a relação entre cinema nacional e cinema negro no feminino, reivindicando que esse último só pode ser considerado como tal se (re)criar espaços-territórios silenciados pelo racismo e pela heteronormatividade por meio de ensinamentos ancestrais e respeito às experiências de vida da comunidade onde estão inseridos.

Daiany Dantas, Isaiana Santos e Renata Nolasco sucedem a discussão sobre as mulheres no cinema brasileiro, abordando no capítulo 13 - "Amor, plástica e barulho: protagonismo e rivalidade feminina como elementos estéticos e narrativos no cinema pernambucano"- o cinema pernambucano contemporâneo. Rememorando o processo de produção e o cenário das narrativas audiovisuais desenvolvidas na arquitetura coletiva que ficou conhecida como "brodagem", as autoras relevam a persistência do ocultamento da participação feminina, atestando que existe machismo mesmo nos ambientes cujo propósito seja a transgressão e a vanguarda. Para tal intento, descrevem dois episódios que causaram constrangimento na cidade de Recife, por se tratarem de chacota pública ao trabalho de pernambucanas realizadoras de cinema. Em seguida, nomeiam algumas dessas cineastas, aferindo o longa Amor, plástico e barulho (2013), de Renata Pinheiro, por problematizar diversas tensões sobre as construções do feminino e as divisões simbólicas entre homens e mulheres.

Denise Tavares, em "Documentário biográfico e protagonismo feminino", foge do estabelecimento de conexões e determinações de uma identidade fixa em produções biográficas de mulheres realizadoras, demonstrando que é preciso reconhecer a multiplicidade de experiências do ser mulher e do documentário biográfico. Para tanto, Tavares assinala como marcas desse tipo de narrativa audiovisual - o pacto do documentário e o pacto da biografia -, acrescentando o inesperado e as ambiguidades próprias das trajetórias femininas presentes em filmes como Um passaporte húngaro (2001), de Sandra Kogut e Elena (2012), de Petra Costa. Ilana Feldman, por sua vez, no capítulo seguinte, "Do pai ao país: o documentário autobiográfico em face do fracasso das esquerdas no Brasil", aborda a potência dos documentários contemporâneos por seu cunho autobiográfico, investigando as experiências pessoais de Maria Clara Escobar e Flavia Castro, filhas de exilados e presos políticos da ditadura civil-militar brasileira, que dirigiram, respectivamente, Os dias com ele (2013) e Diário de uma busca (2011), lançando mão de distintas formas 
de narrar suas buscas pela figura paterna. Cada uma dessas realizadoras, a sua maneira, romperam diversos silêncios históricos e pessoais reconstruindo e reencontrando na memória pessoal e coletiva embates que se apresentam na atualidade da política brasileira, reconhecendo, de certa forma, a vulnerabilidade da nossa democracia e demarcando vazios na nossa história recente, onde há uma precariedade de representação sobre as mulheres. E, no último capítulo, intitulado "Dora e a luta histórica contra os fascismos: subversão e limiar em Retratos de Identificação", Roberta Veiga reforça que a perspectiva histórica do ponto de vista feminino é quase nula e devolve às mulheres, através da valorização do trabalho da cineasta Anita Leandro, em Retratos de identificação (2014) esse direito. Nessa narrativa audiovisual, segundo Veiga, a presença feminina permite afirmar que o engajamento das mulheres na luta pela liberdade, durante a ditadura civil e militar no Brasil, exigiu esforços, primeiro, contra a família e os valores conservadores da esfera privada; em seguida, contra o Estado ditador e; ainda contra o preconceito que existia dentro dos próprios movimentos de luta, transitando entre micro e macro-história, em um jogo, onde passado e presente; pessoal e político; feminino e masculino oscilam nas imagens que constroem (des)certezas sobre o ideal de Joan Scott e a revisão dos paradigmas históricos e sociais e a lógica binária de diferença entre homens e mulheres.

Destacamos, finalmente, que essa coletânea robustece a dimensão de intervenção que o conjunto de seus textos propõe - retirar as mulheres da margem da história do cinema brasileiro - apresentando-se ainda como uma fissura no pensamento crítico feminista no campo do cinema contemporâneo. Leitura obrigatória, "Feminino e plural: mulheres no cinema brasileiro" expõe diversas desigualdades entre homens, mulheres, gays e lésbicas, no campo cinematográfico e na nossa sociedade, podendo cultivar novas investigações e estabelecer relações e associações indispensáveis para potencializar o feminino e as discussões sobre gênero no audiovisual. Uma publicação que dar voz e rosto para diversas mulheres, resgatando e reavaliando seu papel em detrimento a outros recortes excludentes e discriminatórios. 